\section{nephron \\ Clinical}

Practice
Nephron 2017;136:292-297

DOI: $10.1159 / 000455197$
Received: May 20, 2016

Accepted after revision: December 14, 2016

Published online: January 27, 2017

\title{
Risks for All-Cause Mortality: Stratified by Age, Estimated Glomerular Filtration Rate and Albuminuria
}

\author{
David G. Warnock ${ }^{a}$ Pierre Delanaye ${ }^{c}$ Richard J. Glassock ${ }^{b}$ \\ ${ }^{a}$ Department of Medicine, University of Alabama at Birmingham, Birmingham, AL, and ${ }^{\mathrm{b}}$ Department of Medicine, \\ Geffen School of Medicine at UCLA, Los Angeles, CA, USA; ' Nephrology-Dialysis-Transplantation, University of \\ Liège, Liège, Belgium
}

\section{Keywords}

Serum creatinine $\cdot$ Incidence rate ratios $\cdot$ Relative risk .

Absolute risk

\begin{abstract}
The relative reduction of risk for all-cause mortality among the elderly has been described as attenuated compared to younger subjects, but the risk for all-cause mortality increases with age when absolute risk is considered. The objectives of the present inquiry were to calculate the relative and absolute risks of all-cause mortality based on incidence rate ratios, and summarize these risks for age, gender, and race strata. We conclude that strata-specific risk summaries are more informative than a single all-encompassing risk summary, and that gender- and race-specific strata need to be considered as well as age-specific strata.

๑) 2017 S. Karger AG, Basel
\end{abstract}

\section{Introduction}

Chronic kidney disease (CKD) staging, based on estimated glomerular filtration rate (eGFR) categories, was recently revised to include risk strata for urinary albumin-to-creatinine ratio (ACR) [1]. The associations between eGFR and ACR categories by age for all-cause

\section{KARGER}

(C) 2017 S. Karger AG, Basel

E-Mail karger@karger.com

www.karger.com/nef mortality risk and end-stage renal disease (ESRD) have been studied in a meta-analysis [2].

Our objective was to compare relative risks and absolute risks for all-cause mortality among adults stratified by eGFR, ACR, and demographic categories. Previous publications have emphasized an attenuation of relative risk for all-cause mortality for older individuals compared to younger individuals [3-5], and have suggested adoption of an age-calibrated definition of CKD. We now report similar apparent attenuation of relative risk for allcause mortality for female gender and black subjects in the study cohort. Rather than adopting strata-specific definitions of CKD, we believe the same ultimate goal can be achieved by adopting strata-specific risk summaries ("heat maps") to describe the risk for all-cause mortality.

\section{Materials and Methods}

The Reasons for Geographic and Racial Differences in Stroke (REGARDS) study cohort included 30,239 black and white individuals who were $\geq 45$ years, between January 2003 and October $2007[6,7]$. Additional methodological details and description of the cohort are provided elsewhere [6-8]. The present analysis excluded

Contribution from the CME course of the DIABESITY Working Group of the ERA-EDTA, Bergamo, December 4-5, 2015.

Prof. David G. Warnock

Department of Medicine, University of Alabama at Birmingham

Room 614 ZRB, 1720 2nd Avenue South

Birmingham, AL 35294-0007 (USA)

E-Mail dwarnock@uabmc.edu 
Table 1. Baseline characteristics and outcomes for age-strata: 26,887 participants with 3,980 deaths (15\%), excluding participants with missing values

\begin{tabular}{|c|c|c|c|c|}
\hline Characteristics & Total $^{\mathrm{a}}$ & Age: $\leq 60^{\mathrm{a}}$ & Age: $60-70^{\mathrm{a}}$ & Age: $\geq 70^{\mathrm{a}}$ \\
\hline Patients, $n(\%)$ & $26,887(100)$ & $9,384(35)$ & $9,215(34)$ & $8,288(31)$ \\
\hline Age, years, median (IQR) & $64(58-71)$ & $56(52-58)$ & $65(63-67)$ & $75(72-79)^{\mathrm{b}}$ \\
\hline Males, $\%$ & $12,251(46)$ & $3,836(41)$ & $4,322(47)$ & $4,093(49)^{\mathrm{b}}$ \\
\hline Blacks, $\%^{c}$ & $10,670(40)$ & $4,084(44)$ & $3,689(40)$ & $2,897(35)^{b}$ \\
\hline eGFR_creat, $\mathrm{mL} / \mathrm{min} / 1.73 \mathrm{~m}^{2}$, mean $(\mathrm{SD})$ & $86(19)$ & $96(17)$ & $86(17)$ & $74(18)^{b}$ \\
\hline eGFR_creat $<60 \mathrm{~mL} / \mathrm{min} / 1.73 \mathrm{~m}^{2}, \%$ & $2,760(10.3)$ & $260(2.8)$ & $726(7.9)$ & $1,774(21)^{b}$ \\
\hline ACR $>30 \mathrm{mg} / \mathrm{g}, \%$ & $3,796(14)$ & $986(11)$ & $1,207(13)$ & $1,603(19)^{b}$ \\
\hline $\mathrm{SBP}, \mathrm{mm} \mathrm{Hg}$, mean (SD) & $127(17)$ & $124(16)$ & $128(16)$ & $131(17)^{b}$ \\
\hline Total cholesterol, mean (SD) & $192(40)$ & $197(40)$ & $193(40)$ & $187(40)^{b}$ \\
\hline $\mathrm{BMI}, \mathrm{kg} / \mathrm{m}^{2}$, median (IQR) & $28(25-32)$ & $29(25-34)$ & $29(25-33)$ & $27(24-31)^{b}$ \\
\hline CVD, $\%$ & $5,692(21)$ & $1,192(13)$ & $1,944(21)$ & $2,556(31)^{b}$ \\
\hline Diabetes, \% & $5,413(20)$ & $1,627(17)$ & $2,026(22)$ & $1,760(21)$ \\
\hline Current smoking, \% & $3,820(14)$ & $1,860(20)$ & $1,315(14)$ & $645(7.8)^{b}$ \\
\hline \multicolumn{5}{|l|}{ Outcomes, $\%$} \\
\hline Deaths, $\%$ & $3,980(15)$ & $505(5.4)$ & $1,032(11)$ & $2,443(30)^{b}$ \\
\hline Incidence rate, per 1,000 -person years & $21.3(20.7-22.0)$ & $7.7(7.1-8.5)$ & $15.5(14.6-16.5)$ & $45(43-46)^{b}$ \\
\hline Incidence rate ratio & & 1.00 (reference) & $2.00(1.80-2.22)$ & $5.74(5.22-6.32)^{\mathrm{b}}$ \\
\hline
\end{tabular}

Values are given as number (percentage), means (SD); medians (IQR); incidence rates and incidence rate ratios (95\% CI).

ACR, urinary albumin-to-creatinine ratio; BMI, body mass index; CVD, prevalent cardiovascular disease; eGFR_creat, creatininebased estimated glomerular filtration rate, CKD Epidemiology Collaboration; IQR, interquartile range, 25th-75th quartile; SBP, systolic blood pressure.

$p<0.001$, bold text used to indicate significance for comparisons of characteristics to the reference group by ANOVA for means, signed rank test for medians, and chi-square test for proportions.

${ }^{\text {a }}$ Row percentages; all others are column percentages.

${ }^{\mathrm{b}} p<0.05$ for comparison between 3rd and 2nd categories (Dunnett test for multiple comparisons) or chi-square test or proportions.

${ }^{c}$ Race or ethnic group was self-reported, and further classified as black or non-black.

participants with missing values for covariates. The effect variable was the standardized creatinine-based CKD-Epidemiology Collaboration eGFR [9]. All-cause mortality was ascertained as previously described [6-8]. The UAB Institutional Review Board approved the protocol and all participants gave written informed consent.

\section{Mortality Rates, Incidence Rates and Absolute Rates for} All-Cause Mortality

Mortality rates (percentage), incidence rates (per 1,000-person years; Stata command stptime), and incidence rate ratios with $\pm 95 \%$ CIs were calculated with multi-variable adjusted Poisson regression models for eGFR strata $(>100,80-100,60-80,45-60$, and $<45$ $\left.\mathrm{mL} / \mathrm{min} / 1.73 \mathrm{~m}^{2}\right)$, ACR strata $(<30$ and $\geq 30 \mathrm{mg} / \mathrm{g})$, and age strata $(<60,60-70$, and $>70$ years). Absolute incidence rates were obtained from the incidence rate ratios by multiplying each by the rate for eGFR for $80-100 \mathrm{~mL} / \mathrm{min} / 1.73 \mathrm{~m}^{2}, \mathrm{ACR}<30 \mathrm{mg} / \mathrm{g}$, and age $<60$ years [10].

Dunnett method was used for making comparisons with a reference category for pairwise comparisons of means. Incidence rate ratios were calculated with Poisson regression for eGFR deciles between 25 and $125 \mathrm{~mL} / \mathrm{min} / 1.73 \mathrm{~m}^{2}$. Mean values $( \pm 95 \% \mathrm{CI})$ are used as the relative risk for each interval with covariates fixed at their mean values (Stata command margins, atmeans). Stata (version 14.1, College Park Station, TX, USA) was used for statistical analysis.

\section{Results}

\section{Baseline Characteristics}

Baseline characteristics and deaths are shown for the age strata in Table 1 for 26,887 with 3,989 deaths (15\%). Of the entire cohort, $40 \%$ were AfricanAmerican and $25 \%$ were $<58$ years of age at enrollment. Male preponderance, systolic blood pressure, prevalent cardiovascular disease, albuminuria $>30 \mathrm{mg} / \mathrm{dL}$, and eGFR $<60 \mathrm{~mL} / \mathrm{min} / 1.73 \mathrm{~m}^{2}$ increased across the age strata. The number of blacks, total cholesterol, and current smoking status decreased across the age strata. As expected, all-cause mortality rates increased with age.

Risk Summaries for All-Cause Mortality: "Heat Maps"

Table 2 a shows all-cause mortality across age, eGFR, and ACR strata, with the number of deaths expressed as a percentage. Higher mortality rates were associated with lower eGFR categories, and especially for subjects with 
Table 2

a. Counts and all-cause mortality rates: age, eGFR, and ACR strata ${ }^{a}$

\begin{tabular}{|c|c|c|c|c|c|c|}
\hline $\begin{array}{l}\text { eGFR_creat, } \\
\mathrm{mL} / \mathrm{min} / 1.73 \mathrm{~m}^{2}\end{array}$ & \multicolumn{2}{|l|}{ Age: <60 } & \multicolumn{2}{|l|}{ Age: $60-70$} & \multicolumn{2}{|l|}{ Age: $>70$} \\
\hline $80-100$ & $\begin{array}{l}3,825 \\
141(3.7)\end{array}$ & $\begin{array}{l}309 \\
31(10)\end{array}$ & $\begin{array}{l}3,897 \\
315(8.1)\end{array}$ & $\begin{array}{l}418 \\
86(21)\end{array}$ & $\begin{array}{l}2,667 \\
597(22)\end{array}$ & $\begin{array}{l}480 \\
178(37)\end{array}$ \\
\hline $45-60$ & $\begin{array}{l}145 \\
15(10)\end{array}$ & $\begin{array}{l}51 \\
11(22)\end{array}$ & $\begin{array}{l}396 \\
49(12)\end{array}$ & $\begin{array}{l}137 \\
44(32)\end{array}$ & $\begin{array}{l}893 \\
288(32)\end{array}$ & $\begin{array}{l}319 \\
163(51)\end{array}$ \\
\hline$<45$ & $\begin{array}{l}21 \\
3(14)\end{array}$ & $\begin{array}{l}43 \\
20(47)\end{array}$ & $\begin{array}{l}96 \\
20(21)\end{array}$ & $\begin{array}{l}97 \\
61(63)\end{array}$ & $\begin{array}{l}318 \\
139(44)\end{array}$ & $\begin{array}{l}244 \\
171(70)\end{array}$ \\
\hline
\end{tabular}

Values are $n$ or $n(\%)$.

a The mortality rates were calculated as the percentage of deaths in each cell.

b. Relative risk ( $\pm 95 \% \mathrm{CI})$ for all-cause mortality: age, eGFR, and ACR strata ${ }^{\mathrm{b}}$

\begin{tabular}{|c|c|c|c|c|c|c|}
\hline \multirow{2}{*}{$\begin{array}{l}\text { eGFR, } \\
\mathrm{mL} / \mathrm{min} / 1.73 \mathrm{~m}^{2}\end{array}$} & \multicolumn{2}{|l|}{ Age: $<60$} & \multicolumn{2}{|l|}{ Age: $60-70$} & \multicolumn{2}{|l|}{ Age: $>70$} \\
\hline & ACR $<30 \mathrm{mg} / \mathrm{g}$ & ACR $\geq 30 \mathrm{mg} / \mathrm{g}$ & ACR $<30 \mathrm{mg} / \mathrm{g}$ & ACR $\geq 30 \mathrm{mg} / \mathrm{g}$ & ACR $<30 \mathrm{mg} / \mathrm{g}$ & ACR $\geq 30 \mathrm{mg} / \mathrm{g}$ \\
\hline$>100$ & $1.20(0.95-1.52)$ & $2.49(1.77-3.49)$ & $1.12(0.97-1.38)$ & $1.78(1.29-2.45)$ & $0.87(0.67-1.12)$ & $1.57(1.07-2.31)$ \\
\hline $80-100$ & 1.00 (reference) $^{\mathrm{a}}$ & $2.02(1.36-3.01)$ & 1.00 (reference) $^{\mathrm{a}}$ & $2.28(1.79-2.91)$ & 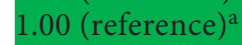 & $1.69(1.42-2.00)$ \\
\hline $60-80$ & $1.58(1.17-2.12)$ & $2.28(1.40-3.73)$ & $1.12(0.94-1.34)$ & $1.92(1.46-2.53)$ & $1.13(1.01-1.26)$ & $1.88(1.60-2.12)$ \\
\hline $45-60$ & $2.11(1.23-3.61)$ & $4.00(2.13-7.51)$ & $1.47(1.08-1.99)$ & $3.21(2.32-4.43)$ & $1.48(1.28-1.70)$ & $2.38(2.00-2.84)$ \\
\hline$<45$ & $2.96(0.94-9.30)$ & $6.80(4.08-11.3)$ & $2.59(1.64-4.08)$ & $7.13(5.36-9.50)$ & $2.22(1.84-2.67)$ & $3.71(3.12-4.42)$ \\
\hline
\end{tabular}

${ }^{a}$ Incidence rate ratio; relative to reference group for each age strata.

Color coding for relative risk of all-cause mortality: green, $<1.5$; yellow, $>1.5$ and $<2.5$; orange, $>2.5$ and $<4.0$; red, $>4.0$. Color version available online.

c. Absolute incidence rate $( \pm 95 \% \mathrm{CI})$ for all-cause mortality: age, eGFR, and ACR strata ${ }^{\mathrm{b}}$

\begin{tabular}{|c|c|c|c|c|c|c|}
\hline \multirow{2}{*}{$\begin{array}{l}\text { eGFR, } \\
\mathrm{mL} / \mathrm{min} / 1.73 \mathrm{~m}^{2}\end{array}$} & \multicolumn{2}{|l|}{ Age: $<60$} & \multicolumn{2}{|l|}{ Age: $60-70$} & \multicolumn{2}{|l|}{ Age: $>70$} \\
\hline & ACR $<30 \mathrm{mg} / \mathrm{g}$ & ACR $\geq 30 \mathrm{mg} / \mathrm{g}$ & ACR $<30 \mathrm{mg} / \mathrm{g}$ & ACR $\geq 30 \mathrm{mg} / \mathrm{g}$ & ACR $<30 \mathrm{mg} / \mathrm{g}$ & ACR $\geq 30 \mathrm{mg} / \mathrm{g}$ \\
\hline$>100$ & $1.23(0.05-2.42)$ & $5.37(3.71-7.04)$ & $4.25(3.05-5.45)$ & $6.99(5.27-8.71)$ & $7.29(5.78-8.80)$ & $10.1(8.02-12.2)$ \\
\hline $80-100$ & $5.13(4.35-6.05)^{*}$ & $4.25(2.26-6.26)$ & $3.32(2.30-4.34)$ & $7.95(6.57-934)$ & $8.40(7.45-9.35)$ & $10.9(9.71-12.0)$ \\
\hline $60-80$ & $2.53(1.02-4.05)$ & $5.30(2.82-7.77)$ & $3.94(2.83-5.05)$ & $7.32(5.80-8.84)$ & $8.99(8.04-9.94)$ & $11.3(10.2-12.4)$ \\
\hline $45-60$ & $4.89(2.15-7.62)$ & $8.21(5.05-11.4)$ & $5.46(3.79-7.13)$ & $9.93(8.14-11.7)$ & $10.3(9.34-11.3)$ & $12.5(11.3-13.7)$ \\
\hline$<45$ & $6.32(0.46-12.2)$ & $11.5(8.96-14.0)$ & $8.47(6.06-10.9)$ & $14.1(12.6-15.7)$ & $12.4(11.1-13.6)$ & $14.8(13.6-16.0)$ \\
\hline
\end{tabular}

${ }^{\text {a }}$ Incidence rate; deaths per 1,000 patient year.

The incidence rate ratios in Table $2 c$ were calculated for each gender and age $>70$ years; the reference group had eGFR $>80$ and $<100 \mathrm{~mL} / \mathrm{min} / 1.73 \mathrm{~m}^{2}$ and ACR $<30 \mathrm{mg} / \mathrm{g}$ creatinine.

Color coding for absolute risk of all-cause mortality: green, $<6.0$; yellow, $>6.0$ and $<8.0$; orange, $>8.0$ and $<12.0$; red, $>12.0$. Color version available online.

The absolute mortality rates (Table $3 \mathrm{~b}$ ) for each cell were obtained by multiply the incidence rate ratios by the mortality rate for the eGFR $80-100$, ACR $<30 \mathrm{mg} / \mathrm{g}$ group in column 1 (indicated by*).

ACR, urinary albumin-to-creatinine ratio; eGFR, creatinine-based estimated glomerular filtration rate. 
Table 3

a. Relative risk $( \pm 95 \% \mathrm{CI})$ for all-cause mortality: race, age $>70$, eGFR, and ACR strata ${ }^{\text {a }}$

\begin{tabular}{|c|c|c|c|c|c|c|}
\hline $\begin{array}{l}\text { eGFR, } \\
\mathrm{mL} / \mathrm{min} / 1.73 \mathrm{~m}^{2}\end{array}$ & \multicolumn{2}{|l|}{ Age: $>70$} & \multicolumn{2}{|l|}{ Age: $>70$; white } & \multicolumn{2}{|l|}{ Age: $>70$; black } \\
\hline $80-100$ & 1.00 (reference) $^{\mathrm{a}}$ & $1.69(1.42-2.00)$ & 1.00 (reference) $^{\mathrm{a}}$ & $1.83(1.49-2.24)$ & 1.00 (reference) $^{\mathrm{a}}$ & $1.45(1.08-1.96)$ \\
\hline $60-80$ & $1.13(1.01-1.26)$ & $1.88(1.60-2.12)$ & $1.10(0.96-1.26)$ & $1.87(1.53-2.28)$ & $1.17(0.95-1.44)$ & $1.90(1.44-2.50)$ \\
\hline $45-60$ & $1.48(1.28-1.70)$ & $2.38(2.00-2.84)$ & $1.54(1.30-1.81)$ & $2.34(1.88-2.82)$ & $1.34(1.03-1.75)$ & $2.42(1.80-3.26)$ \\
\hline
\end{tabular}

b. Relative risk for all-cause mortality: gender, age $>70$, eGFR, and ACR strata ${ }^{\text {a }}$

\begin{tabular}{|c|c|c|c|c|c|c|}
\hline \multirow{2}{*}{$\begin{array}{l}\mathrm{eGFR} \text {, } \\
\mathrm{mL} / \mathrm{min} / 1.73 \mathrm{~m}^{2}\end{array}$} & \multicolumn{2}{|l|}{ Age: $>70$} & \multicolumn{2}{|l|}{ Age: $>70$; males } & \multicolumn{2}{|l|}{ Age: $>70$; females } \\
\hline & ACR $<30 \mathrm{mg} / \mathrm{g}$ & ACR $\geq 30 \mathrm{mg} / \mathrm{g}$ & $\mathrm{ACR}<30 \mathrm{mg} / \mathrm{g}$ & $\mathrm{ACR} \geq 30 \mathrm{mg} / \mathrm{g}$ & ACR $<30 \mathrm{mg} / \mathrm{g}$ & ACR $\geq 30 \mathrm{mg} / \mathrm{g}$ \\
\hline$>100$ & $0.87(0.67-1.12)$ & $1.57(1.07-2.31)$ & $1.27(0.91-1.77)$ & $1.25(0.70-2.25)$ & $0.57(0.38-0.87)$ & $1.95(1.17-3.27)$ \\
\hline $80-100$ & 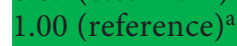 & $1.69(1.42-2.00)$ & $1.00(\text { reference })^{\mathrm{a}}$ & $1.72(1.38-2.14)$ & 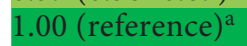 & $1.68(1.29-2.20)$ \\
\hline $60-80$ & $1.13(1.01-1.26)$ & $1.88(1.60-2.12)$ & $1.21(1.05-1.40)$ & $1.91(1.55-2.34)$ & $1.00(0.83-1.20)$ & $1.90(1.46-2.46)$ \\
\hline $45-60$ & $1.48(1.28-1.70)$ & $2.38(2.00-2.84)$ & $1.62(1.34-1.95)$ & $2.54(2.04-3.17)$ & $1.30(1.05-1.62)$ & $2.15(1.61-2.88)$ \\
\hline$<45$ & $2.22(1.84-2.67)$ & $3.71(3.12-4.42)$ & $2.57(1.98-3.35)$ & $3.47(2.75-4.38)$ & $1.87(1.43-2.43)$ & $4.12(3.18-5.35)$ \\
\hline
\end{tabular}

${ }^{\text {a }}$ Incidence rate ratio; relative to the reference group for each age strata.

Color coding for absolute risk of all-cause mortality: light green, $<1.0$; green, $>1$ and $<1.5$; yellow, $>1.5$ and $<2.5$; orange, $>2.5$ and $<4.0$; red, $>4.0$. Color version available online.

ACR, urinary albumin-to-creatinine ratio; eGFR, creatinine-based estimated glomerular filtration rate [9].

ACR $>30 \mathrm{mg} / \mathrm{g}$. As expected, higher mortality rates were observed with increasing age categories for all strata.

Relative risks for mortality across the age strata, relative to a common reference at eGFR between 80 and 100 $\mathrm{mL} / \mathrm{min} / 1.73 \mathrm{~m}^{2}$ and ACR $<30 \mathrm{mg} / \mathrm{g}$ are shown in Table $2 \mathrm{~b}$. Arbitrary color coding corresponds to increasing relative risk (see legend). The relative risk for all-cause mortality was attenuated for older subjects, and the relative risk is similar for eGFR strata $>45 \mathrm{~mL} / \mathrm{min} / 1.73 \mathrm{~m}^{2}$ and ACR $<30 \mathrm{mg} / \mathrm{g}$.

Table $2 c$ shows the absolute risk for mortality across the age strata. Incidence rate ratios were calculated relative to a common reference at eGFR between 80 and $100 \mathrm{~mL} / \mathrm{min} / 1.73 \mathrm{~m}^{2}$, ACR $<30 \mathrm{mg} / \mathrm{g}$, and age $<60$ years. Arbitrary color coding corresponds to increasing absolute risk (see legend). The absolute risk for allcause mortality was increased for older REGARDS participants (age $>70$ years), and the absolute risk was similar for eGFR strata $>45 \mathrm{~mL} / \mathrm{min} / 1.73 \mathrm{~m}^{2}$, and ACR $<30 \mathrm{mg} / \mathrm{g}$ was similar for subjects $<70$ years. The absolute risk for mortality increased with age and ACR $>30 \mathrm{mg} / \mathrm{g}$.

Demographics, CKD and All-Cause Mortality
Table 3 shows the relative risk for mortality for race and gender strata, among subjects $>70$ years of age. Arbitrary color coding corresponds to increasing absolute risk (see legend). The relative risk for all-cause mortality was attenuated for black subjects compared to white subjects $>70$ years of age (Table $3 a$ ), and for female subjects compared to male subjects $>70$ years of age and ACR $<30 \mathrm{mg} / \mathrm{g}$ (Table $3 \mathrm{~b}$ ).

\section{Discussion}

We describe mortality risk for REGARDS participants based on demographic strata, eGFR, and ACR categories using incidence rates and incidence rate ratios for allcause mortality. Risk summaries ("heat maps") show notable differences across demographic strata.

The relative risks for all-cause mortality were attenuated for the older age strata (Table $2 b$ ), while the absolute risk for mortality increased with age (Table 2c). For example, the relative risks for mortality among participants with eGFR $>60$ and $<80 \mathrm{~mL} / \mathrm{min} / 1.73 \mathrm{~m}^{2}$, and

Nephron 2017;136:292-297 DOI: $10.1159 / 000455197$ 
ACR $<30 \mathrm{mg} / \mathrm{g}$ was 1.58 (95\% CI 1.17-2.12) for age $<60$ years; 1.12 (95\% CI $0.94-1.34$ ) for age $>60$ and $<70$ years; and 1.13 (95\% CI 1.01-1.26) for age $>70$ years (Table $2 \mathrm{~b}$ ). In contrast, the absolute risk for mortality among the same participants was increased across the age strata: 2.53 (95\% CI 1.02-4.05) for age <60 years; 3.94 (95\% CI 2.83-5.05) for age $>60$ and $<70$ years; and 8.99 (95\% CI 8.04-9.94) for age $>70$ years (Table $2 c$ ). Similar patterns were seen across the same eGFR and age strata for ACR $>30 \mathrm{mg} / \mathrm{g}$.

Previous commentaries have emphasized the attenuation of the relative risk for all-cause mortality among older subjects [4]. The present analysis confirms this finding, but also extends the analysis to show the expected increase in absolute risk for all-cause mortality with increasing age. Similar observations about the increase in mortality rates with age and ACR levels are described by Hallan et al. [2].

Furthermore, the gender and race differences in relative risk for all-cause mortality shown in Table $3 a$ and $b$ suggest that these strata as well as age should also be considered when assessing the relative risk for all-cause mortality among a specified cohort of patients. This conclusion is consistent with longitudinal descriptions of the risk for all-cause mortality described for elderly Swedish women [11].

The KDIGO Controversies Conference Report [10] included "heat maps" for separate outcome events, including all-cause mortality, cardiovascular mortality, ESRD, acute kidney injury, and progressive CKD. The relative risk summary table for all-cause mortality [10] is similar to the absolute risk summary. It used similar reference groups (ACR $<10$ and $<30 \mathrm{mg} / \mathrm{g}$, eGFR 90-105 and $80-100 \mathrm{~mL} / \mathrm{min} / 1.73 \mathrm{~m}^{2}$ ), with mortality incidence rates of 7.0 and 5.13 deaths per 1,000-person years, respectively. Absolute risk in Table $2 \mathrm{c}$ was generated by multiplying incidence rate ratios by the absolute risk for the reference group, as previously described [10]. As expected, the risk for all-cause mortality increased with aging.

With the goal of confirming a single all-encompassing risk summary scheme [1], Hallan et al. [2] examined risk summaries for age strata, eGFR, and ACR categories with a meta-analysis of 33 general population cohorts, including over 2 million participants with 112,325 deaths, including 27,306 REGARDS participants. Risk for all-cause mortality differ across age strata, both for relative risk and absolute risk [2], supporting the use of different risk summaries for different outcome events, demographic strata, and eGFR and ACR strata.
We conclude that the differences between relative and absolute risks for all-cause mortality have not received sufficient emphasis. Furthermore, there may be differences in the absolute and relative risks across age-strata that require further analyses for gender and race strata. The REGARDS cohort is not large enough to fully define these strata, and was recruited with the goal of including subjects $>45$ years of age, and an equal number of men, women, and white and black participants. Additional meta-analysis of combined general population cohorts seems worthwhile.

It has been proposed that the cutpoints for CKD stages be adjusted for age strata, described as an age-calibrated definition of CKD [3-5], to account for the attenuation of relative risk for all-cause mortality observed with older subjects. This approach has not been widely accepted [12], and represents a post-hoc modification of risk assessment that does not address the underlying weaknesses inherent when such analyses include eGFR as an effect variable [8]. The current proposal to use separate heat maps for age, race, and gender strata rather than a single all-encompassing risk summary may accomplish the basic goal of providing risk assessments in CKD that reflect the demographic and kidney-specific factors for an individual patient.

\section{Acknowledgments}

This research project is supported by a cooperative agreement U01 NS041588 from the National Institute of Neurological Disorders and Stroke, National Institutes of Health, Department of Health and Human Service. The content is solely the responsibility of the authors and does not necessarily represent the official views of the National Institute of Neurological Disorders and Stroke or the National Institutes of Health. Representatives of the funding agency have been involved in the review of the manuscript but not directly involved in the collection, management, analysis or interpretation of the data. The authors thank the other investigators, the staff, and the participants of the REGARDS study for their valuable contributions. A full list of participating REGARDS investigators and institutions can be found at http://www.regardsstudy.org.

The support of the UAB/UCSD O'Brien Center for Kidney Research (P30 DK079337) is acknowledged.

Additional funding was provided by an investigator-initiated grant-in-aid from Amgen Corporation. Amgen did not have any role in the design and conduct of the study or the preparation of the manuscript.

\section{Disclosure Statement}

The authors have no conflicts of interest to declare.
Warnock/Delanaye/Glassock 


\section{References}

1 Kidney Disease: Improving Global Outcomes (KDIGO) CKD Work Group: KDIGO 2012 clinical practice guideline for the evaluation and management of chronic kidney disease. Kidney Int Suppl 2013;3:1-150.

2 Hallan SI, Matsushita K, Sang Y, Mahmoodi BK, Black C, Ishani A, Kleefstra N, Naimark D, Roderick P, Tonelli M, Wetzels JF, Astor BC, Gansevoort RT, Levin A, Wen CP, Coresh J; Chronic Kidney Disease Prognosis Consortium: Age and association of kidney measures with mortality and end-stage renal disease. JAMA 2012;308:2349-2360.

3 Glassock R, Delanaye P, El Nahas M: An agecalibrated classification of chronic kidney disease. JAMA 2015;314:559-560.

4 Delanaye P, Glassock RJ, Pottel H, Rule AD: An age-calibrated definition of chronic kidney disease: rationale and benefits. Clin Biochem Rev 2016;37:17-26.
5 Denic A, Glassock RJ, Rule AD: Structural and functional changes with the aging kidney. Adv Chronic Kidney Dis 2016;23:19-28.

6 Howard VI, Cushman M, Pulley L, Gomez CR, Go RC, Prineas RJ, Graham A, Moy CS, Howard G: The reasons for geographic and racial differences in stroke study: objectives and design. Neuroepidemiology 2005;25: 135-143.

7 Howard VJ, Kleindorfer DO, Judd SE, McClure LA, Safford MM, Rhodes JD, Cushman M, Moy CS, Soliman EZ, Kissela BM, Howard G: Disparities in stroke incidence contributing to disparities in stroke mortality. Ann Neurol 2011;69:619-627.

8 Warnock DG: Estimated glomerular filtration rate: fit for what purpose? Nephron 2016 134:43-49.

9 Inker LA, Schmid CH, Tighiouart H, Eckfeldt JH, Feldman HI, Greene T, Kusek JW, Man- zi J, Van Lente F, Zhang YL, Coresh J, Levey AS; CKD-EPI Investigators: Estimating glomerular filtration rate from serum creatinine and cystatin C. N Engl J Med 2012;367:2029.

10 Levey AS, de Jong PE, Coresh J, El Nahas M Astor BC, Matsushita K, Gansevoort RT, Kasiske BL, Eckardt KU: The definition, classification, and prognosis of chronic kidney disease: a KDIGO controversies conference report. Kidney Int 2011;80:17-28.

11 Malmgren L, McGuigan FE, Berglundh S, Westman K, Christensson A, Akesson K: Declining estimated glomerular filtration rate and its association with mortality and comorbidity over 10 years in elderly women. Nephron 2015;130:245-255.

12 Levey AS, Inker LA, Coresh J: Chronic kidney disease in older people. JAMA 2015;314:557558 . 